\title{
REPRESENTAÇÕES DA INFÂNCIA EM MEMÓRIAS E AUTOBIOGRAFIAS - MINAS GERAIS (1900-1960)
}

DOI: http://dx.doi.org/10.1590/2236-3459/49458

\author{
Simone Aparecida Neves \\ Universidade Federal de Minas Gerais, Brasil. \\ Ana Maria de Oliveira Galvão \\ Universidade Federal de Minas Gerais, Brasil.
}

\begin{abstract}
Resumo
Neste artigo se analisa as experiências de infância reconstruídas em autobiografias e memórias escritas por sujeitos que viveram essa fase da vida em Minas Gerais, no período compreendido entre 1900 e 1960, com o intuito de perceber de que modo diferentes pertencimentos - de gênero, classe social, raça/etnia, origem geográfica - podem influenciar na construção de representações sobre a infância. Foram utilizadas como fontes doze memórias e autobiografias, além de dados demográficos do período. Fundamentado nos estudos sobre a sociologia e a historiografia da infância, evidencia-se a existência de múltiplas infâncias engendradas pelas diferentes interações entre a criança e os diversos contextos históricos e sócio-culturais.

Palavras-chave: história da infância, memórias e autobiografias, história da educação.

\section{REPRESENTATIONS OF CHILDHOOD IN MEMOIRS AND AUTOBIOGRAPHIES - MINAS GERAIS (1900-1960)}

\begin{abstract}
This article examines the experiences of childhood rebuilt in autobiographies and memoirs written by people who lived this period of life, in Minas Gerais, between 1900 and 1960. It aims to analyse how different affiliations - gender, social class, race/ethnicity, geographic origin - can influence the construction of representations of childhood. We used as sources twelve memoirs and autobiographies, as well as demographic data for the period. Based on studies of sociology and historiography, the article shows the existence of multiple childhoods engendered by different interactions between the child and the different historical and socio-cultural contexts. Key-words: history of childhood, memoirs and autobiographies, history of education.
\end{abstract}




\section{REPRESENTACIONES DE LA INFANCIA EM MEMORIAS E AUTOBIOGRAFÍAS (MINAS GERAIS 1900-1960)}

\section{Resumen}

El presente artículo analiza las experiencias de la infancia reconstruidas en autobiografías y memorias escritas por sujetos que vivieron esa etapa de la vida en Minas Gerais, en el período comprendido entre 1900 y 1960, en razón de percibir de qué modo diferentes pertenencias - de género, clase social, raza/etnia, origen geográfico, entre otros - pueden influir en la construcción de representaciones sobre la niñez. Se han utilizado como fuentes doce memorias y autobiografías, además de datos demográficos del período. Fundamentado en los estudios sobre la sociología y la historiografía de la infancia, el artículo evidencia la existencia de múltiples infancias engendradas por las diferentes interacciones entre el niño y los diversos contextos históricos y socio-culturales.

Palabras-clave: historia de la infancia, memorias y autobiografías, historia de la educación.

\section{REPRÉSENTATIONS DE L'ENFANCE DANS LES MÉMOIRES ET AUTOBIOGRAPHIES - MINAS GERAIS (1900-1950)}

\section{Résumé}

Cet article examine les expériences de l'enfance reconstruits dans les autobiographies et les mémoires écrits par des personnes qui ont vécu cette étape de la vie, dans le Minas Gerais, dans la période comprise entre 1900 et 1960, en vue de réaliser comment les différentes affiliations sexe, la classe sociale, la race/ethnicité, origine géographique, entre autres - peuvent influencer la construction des représentations de l'enfance. Ont été utilisés comme sources douze mémoires et autobiographies, ainsi que des données démographiques pour la période. Basé sur des études de sociologie et de l'historiographie de l'enfance l'article montre l'existence de multiples enfances engendrés par différentes interactions entre l'enfant et les différents contextes historiques et socioculturelles.

Mots-clé: histoire de l'enfance, mémoires et autobiographies, histoire de l'éducation. 


\section{Introdução}

pesquisa que originou este artigo teve como objetivo analisar as experiências
de infância reconstruídas em autobiografias e memórias escritas por sujeitos
que viveram essa fase da vida em Minas Gerais, no período compreendido entre 1900 e 1960, com intuito de perceber de que modo diferentes pertencimentos - de gênero, classe social, raça/etnia, origem geográfica - podem influenciar na construção de representações sobre a infância ${ }^{1}$. Tendo em vista o fato de que grande quantidade dos trabalhos existentes no campo da história da infância focalizam iniciativas relativas à assistência à infância (Kuhlmann Jr., 2010), acreditamos que trabalhos que utilizem memórias e autobiografias como fontes podem ampliar a percepção sobre os modos de se viver esse período da vida e nos oferecer pistas, ou mesmo "um vislumbre do que pode ser uma criança" no período analisado (Gullestad, 2010, p. 527).

Nesta direção foram utilizadas para o estudo 12 memórias e autobiografias, das quais quatro obras possuem em seus títulos a palavra infância e oito possuem capítulos ou pequenos textos dedicados à infância. As obras foram lidas e os dados analisados de acordo com categorias que nos permitissem identificar especificidades ou convergências entre as experiências relatadas. Depois de coletadas as fontes foram entrecruzadas com dados demográficos sobre o período, disponíveis, sobretudo, na Enciclopédia dos municípios mineiros do Instituto Brasileiro de Geografia e Estatística e analisados à luz de perspectivas teóricas que problematizam a noção de infância.

Os sujeitos cujas memórias e autobiografias analisamos nesse trabalho viveram suas infâncias em Minas Gerais, nos municípios de Antônio Dias, Araxá, Belo Horizonte, Bocaiúva, Campos Gerais, Conselheiro Lafaiete, Conselheiro Pena, Contagem, Curvelo, Diamantina e Ibiracatu, no período compreendido entre 1900 a 1960. Tais sujeitos tiveram diferentes atuações profissionais - carpinteiro, médico, professor, dona de casa, açougueiro - e escreveram suas obras com diferentes finalidades: prestar homenagem aos pais, relatar os principais momentos da vida para as próximas gerações, exercitar a memória, falar sobre o tempo de infância para os netos. Os livros são escritos em forma de uma única narrativa ou sob a forma de coletânea de crônicas autobiográficas e são, para grande parte desses sujeitos, a única produção bibliográfica de suas vidas. Por isso, são publicados em pequenas editoras e, em alguns casos, editados e distribuídos pelos próprios autores.

Utilizamos como metodologia a pesquisa histórica na perspectiva da história cultural. Como aponta Pesavento (2003, p. 10), tal abordagem nos permite "pensar a cultura como um conjunto de significados partilhados e construídos pelos homens para explicar o mundo." Baseamo-nos, particularmente, no conceito de representação, cunhado por Chartier (1990), a fim de apreender e compreender o modo como os sujeitos investigados, e que ocupam diferentes posições no mundo social, nomeiam e conferem sentido às experiências vivenciadas na infância como uma etapa da vida. A história cultural permite à

\footnotetext{
1 A autobiografia pode ser compreendida como um relato retrospectivo em prosa que uma pessoa real faz de sua própria existência, pondo ênfase em sua vida individual e, em particular na história de sua personalidade (Frago, 2000). As memórias são os relatos que não estão centrados nos acontecimentos introspectivos, mas no mundo exterior, nos acontecimentos e personagens que se recordam.
} 
historiografia da educação o trabalho com temáticas e fontes que nos ajudam a reconstruir sentidos conferidos ao mundo e que se manifestam em palavras, coisas, objetos, imagens, práticas².

No primeiro momento do artigo argumentamos que a infância é uma construção histórica e social. Em seguida discutimos acerca do trabalho com as memórias e autobiografias como fontes para se investigar a infância. Por fim, apresentamos as múltiplas infâncias apreendidas por meio das experiências relatadas e reconstruídas pelos diferentes sujeitos investigados.

\section{Infância: uma construção histórica e social}

Durante muito tempo as crianças estiveram entre os sujeitos esquecidos da história. É com o clássico trabalho, L'enfant et La vie familiale sous l'ancien régime, de Philippe Ariès, publicado na França em 1960, que se inaugurou o campo de investigação historiográfica denominado história da infância. Embora tenha suscitado uma série de críticas no universo acadêmico, conforme sugerem Rocha e Gouvêa (2010), a obra de Ariès representa um marco importante na medida em que possibilita o olhar transdisciplinar sobre a infância, ampliando-se a possibilidade de apreensão da singularidade desse período que ultrapassa as perspectivas biologizante e essencialista predominantes até então.

Na atualidade Galvão e Lopes (2010) afirmam que a história da infância situa-se em um cruzamento de diversas áreas do conhecimento: História, Psicologia, Pedagogia e Antropologia, o que contribui para ampliar o olhar sobre a infância em outros tempos e outras sociedades. A história da infância configura-se como a história da relação da sociedade, da cultura, dos adultos, com essa classe de idade (Kuhlmann Jr.; Fernandes, 2004).

Graças a esses estudos sabemos que a percepção que temos de infância constituída por várias especificidades que a difere da fase adulta - foi sendo construída ao longo da história. Para Veiga (2004) a lógica da modernidade representa um fenômeno histórico importante para a construção dessa percepção, na medida em que introduz na vida social dimensões de mudança e de desestruturação dos costumes, fazendo emergir, inclusive, um novo olhar sobre a criança e a infância. É com a modernidade que se tem o ápice da propagação dos saberes médicos e psicológicos a respeito das diferentes fases pelas quais os seres humanos passam no decorrer da vida. Constrói-se, assim, uma consciência segmentada e mais linear da existência, na qual a criança passou a ser vista como um indivíduo por si mesmo.

Veiga (2004) salienta, ainda, que as constantes mudanças ocasionadas pela modernidade repercutiram de modo a intensificar o investimento na infância, na criança, a fim de formar um sujeito cada vez mais civilizado. Para a autora esse investimento na produção de novas identidades do mundo moderno construiu, também, a concepção de

\footnotetext{
2 Nas últimas décadas também pesquisadores vinculados à História Social têm utilizado autobiografias como forma de se aproximar do cotidiano das pessoas comuns. Ver, por exemplo, Vincent $(1981,1993)$, Graff (1994) e Humphries (2010). 
adulto como autoridade, com função diferenciada na dinâmica geracional: civilizar as crianças, o que repercutiu intensamente no processo educativo e na produção de especificidades próprias à infância, as quais percebemos na atualidade.

\section{A infância nas narrativas de vida escritas por adultos}

Como mostra Frago (2000), não somente os anos de infância, como também a adolescência e juventude, constituem tema central dos primeiros capítulos de número significativo de autobiografias e memórias. Embora as reminiscências de infância constituam uma parte crucial de muitas histórias de vida modernas, tanto autobiografias escritas, quanto histórias de vida produzidas por meio de entrevistas, Gullestad (2005) afirma que esse fato tem sido muito mal estudado e teorizado.

Para a autora dois argumentos principais são citados contra o uso das autobiografias como meio para entender as experiências de infância: primeiro, o fato de que as experiências e as preocupações do autor no tempo da escrita dão outras cores às lembranças de infância, tornando as experiências de vida inerentemente instáveis. Em segundo lugar a distância no tempo, o que faz com que as memórias de infância sejam meio esquecidas e obscuras. Todavia, Gullestad (2005) salienta que, mesmo através da imaginação poética da história do adulto pode-se, às vezes, vislumbrar algo de como é ser criança. Isso porque

numa autobiografia, a parte da infância pode ser lida como o produto de um diálogo entre a criança que o autor foi e o adulto que ele ou ela é então. As memórias de infância não são apenas parcialmente esquecidas, também são parcialmente lembradas. [...] Como todas as memórias, as de infância não são apenas inerentemente instáveis, como também um tanto contínuas. Portanto, a questão mais interessante passa a ser o que é lembrado e selecionado como apresentável numa história de vida. (p. 524)

Logo, para Gullestad (2005), estudar a infância significa, especialmente nas histórias de vida, captar como esse ser criança se concebe e se articula diferentemente em ideias e práticas culturalmente específicas que se unem para definir a natureza de uma infância particular.

Nesse sentido, não deveríamos falar a respeito do estudo da infância, mas antes, e sempre, do estudo de infâncias específicas. Segundo Gullestad (2005) as reminiscências de infância demonstram, particularmente, que a infância não é apenas percebida como um estágio ou um período de tempo na vida de cada um, mas também como uma manifestação de certas qualidades de vida inerentes à ideia moderna de infância, tais como: noções de proteção, amor e brincadeiras em oposição a trabalho duro e sofrimento.

Os adultos, ao demarcarem suas vidas como crianças, o fazem segundo a sua individualidade, mas também e, principalmente, segundo representações partilhadas por grupos identitários com os quais se identificam em virtude, por exemplo, de sua classe social, gênero, raça/etnia, origem geográfica, escolarização e relação com culturas do escrito, como evidenciaremos a seguir. 


\section{Múltiplas infâncias: infância de menino e infância de menina}

Das doze obras estudadas, oito foram escritas por mulheres e quatro por homens. Percebeu-se que ser homem ou mulher aparece nessas fontes como fator que influencia no modo como cada um demarca e descreve a criança que foi no passado. Partindo do que é recontado percebe-se que tal influência era marcada, principalmente, pelos modos de brincar e nos tipos de brinquedos utilizados, bem como nas aprendizagens vivenciadas pelas crianças no contexto das famílias.

No tocante aos brinquedos José H. Diniz (2001 p. 25), tendo vivido uma infância pobre em Contagem por volta de 1940, assim escreve: "No geral era carrinho de madeira para os meninos e bonecas para as meninas." Vanda F. Queiroz, que também viveu sua infância por volta dos anos 1940, porém na zona rural, próxima a Vila Ibiracatu nos dá pistas sobre o cotidiano dos meninos que moravam em seu entorno: "Quando ficavam à toa, andavam pelo mato, de bodoque em punho, caçando e armando arapucas. [...] Coisas de menino homem" (Queiroz, 1997, p. 69).

Embora essa distinção entre brinquedos e brincadeiras de menino e de menina seja evidente em algumas obras, Pitucha G. Renault, mesmo deixando clara tal distinção, relata que no espaço, Belo Horizonte, e no tempo, anos 1940, em que viveu sua infância, a barreira do gênero não era tão fixa, sendo por ela transposta ao imitar os meninos em suas brincadeiras:

Naquele tempo, eu é que invejava um pouco os meus irmãos homens. [...] Eles podiam fazer tudo que quisessem que não fazia mal, eram homens... Aí comecei a imitá-los nas suas brincadeiras. Soltava papagaios, construía o meu carrinho de rolimã, brincava de bentialtas, e tirava rancas no passeio com bola de meia e inventei para mim, o nome de Jorge, de tanto que eu queria ser menino e livre como eles. (Renault, [19-], p.38)

No que se refere ao aprendizado na família Beatriz B. Martins (2000) relata que em casa era incentivada a aprender certas habilidades associadas ao feminino, como costurar. Tal aprendizado era feito principalmente pela revista francesa Ma Poupeé que a mãe assinava mensalmente para ela. Além de modelos a revista trazia material e moldes para roupas de bonecas o que, segundo a autora, a ajudou no aprendizado da costura. Já Vanda F. Queiroz (1997, p.125) aprendeu a bordar com a mãe: "Mãe decidiu que estava na hora de ensinar-me a bordar. [...] Ensinou-me a enfiar a agulha, dar nó e fazer os pontos elementares."

Por meio dos relatos acima podemos inferir que, embora meninos e meninas em alguns casos partilhassem as mesmas brincadeiras, era na participação nas tarefas que envolviam o cotidiano do mundo privado que se distinguiam os fazeres masculinos e femininos. Nesse sentido, enquanto eram ensinadas às meninas certas prendas necessárias ao ambiente doméstico, os meninos ficavam mais próximos do cotidiano dos adultos do sexo masculino, como aponta Carlos C. Filho (1986, p. 31), ao mencionar a convivência com o avô paterno: "me levava para todos os lugares aonde ia: como passar o dia na fazenda, tomando conta dos camaradas na roça, dos peões que lidavam com o gado para separar, tratar, curar, capar." 
Segundo Maluf e Mott (1995), as primeiras décadas do século 20 foram marcadas pela construção e difusão de representações do comportamento feminino ideal, limitando o horizonte da mulher ao espaço do lar. As mulheres foram identificadas ao papel de rainha do lar sustentado pelo tripé mãe-esposa-dona de casa. Sob esse ponto de vista as fontes analisadas neste estudo indicam que o processo de socialização das crianças refletia, em certa medida, as representações difundidas nesse período em que "não haveria realização possível para as mulheres fora do lar, nem para os homens dentro de casa, já que a eles pertenceria a rua e o mundo do trabalho" (Maluf; Mott, 1995, p. 374). Podemos afirmar que essa representação ultrapassava outros pertencimentos, como o de classe, de origem geográfica, étnico/racial e de níveis de escolaridade. Ser menino ou ser menina parecia decisivo no modo como se vivia e, anos depois, se reconstruiria a infância no período estudado.

\section{Infância, pertencimento social e étnico}

O pertencimento étnico dos autores é o dado de mais difícil apreensão nas memórias e autobiografias. Salvo a obra Memórias de um carpinteiro, em que Luís G. dos Santos declara ser descendente de escravos negros africanos, as demais obras nos dão apenas pistas, ora escritas, ora por meio de fotografias, sobre tal pertencimento. Com base nesses indícios, é possível afirmar apenas que das 12 obras apenas uma foi escrita por um homem que se autodeclarava negro e as demais provavelmente por pardos ou brancos. Luiz G. Santos (1963) assim relata:

Em Diamantina não havia muito preconceito de cor, entre seu povo somente se via em assuntos religiosos como, por exemplo, na Ordem do Carmo não se aceitavam pretos, o mesmo na do Santíssimo, nas das Igrejas do Amparo, na das Mercês e do São Francisco frequentavam mulatos, na do Rosário e da Luz pretos por causa da escravidão da origem da raça; portugueses e africanos isto em todo o Brasil. (p. 47)

De acordo com Valente (2011), a decadência dessas ordens ocorreu com o fim da escravidão e o advento da República em 1889. Tendo nascido em 1898 Luiz G. Santos nos oferece indícios de como essas organizações ainda contribuíam para a segregação racial da sociedade diamantinense na primeira década do século 20 . Todavia, percebe-se no relato do autor certa contradição, haja vista que não obstante a menção a essa divisão entre pretos, brancos e mulatos ocorrida nas ordens religiosas ele conta que "em esportes, naquele tempo não havia nenhuma separação; os meninos pobres e pretos misturavam-se com os ricos para as suas proezas e molecagens tão naturais do seu tempo" (Santos, 1963, p. 47).

A afirmação acima nos faz pensar que não existia distinção entre a infância de negros e não negros. Essa contradição expressa por Luís G. dos Santos (1963) pode ser entendida do ponto de vista da ideia de democracia racial em que o discurso apresenta o Brasil como "um país no qual a interpenetração de etnias e culturas aconteceu de um modo verdadeiramente exitoso, o que levou à formação de uma sociedade sem rígidas categorizações raciais e sem intensos preconceitos" (Melo, 2009, p. 287). Muito difundido no século 20 pela obra Casa grande e senzala, de Gilberto Freyre, tal discurso nos faz crer que a convivência e aproximação das raças gerou uma cultura de tolerância racial, 
quando, na verdade, a tensão entre pretos e brancos sempre esteve posta na sociedade brasileira, como fica perceptível nos relatos de Carlos C. Filho e Maria C. M. Rocha. Sendo descendente de italianos e tendo vivido sua infância em Campos Gerais na primeira década do século 20, Carlos C. Filho (1986, p. 55) relata "os pretos de um lado da rua, os brancos de outro. Preto não punha pé de jeito nenhum no meio dos brancos. Era o dito que funcionava fortemente: "lé com lé, cré com cré". O relato de Maria C. M. Rocha (1992), quando se refere à festa de Nossa Senhora do Rosário, aponta na mesma direção:

A festa constava de uma missa e de procissão, no que se referia a parte religiosa. Seguia-se o que mais caía no gosto do povo, ou seja, a dança do Congado, que era uma herança da África, para o Brasil no tempo da escravidão. [...] Lembro da vez que fui à festa em companhia de Andrelina, [...]. Quando Papai ficou sabendo que eu tinha ido àquela festa zangou-se, porque não queria que me misturasse com o povão e participasse de festejos tão populares. (p. 50)

Os excertos acima mostram que o pertencimento étnico/racial pode ser visto como um fator que influenciava no modo como negros e não negros vivenciavam a infância, tendo inclusive, espaços de sociabilidade distintos para cada raça/etnia.

Se, no conjunto das fontes, a voz da infância negra é representada apenas por Luís G. dos Santos, é por outras vozes que se apreendem dados importantes sobre a relação etnia e infância, como no relato de Domitila Borges ([19-]) acerca do menino negro que sua família acolhera para criar:

Quando ele chegou, cheio de vermes, ignorante e semi-nu [sic], mamãe recebeu e cuidou dele. [...] Tinha já uns doze anos. Mamãe o fez frequentar a escolinha de D. Lulu [...] Fora do horário das aulas, Tião, [...], era uma providência para nós. Morávamos um pouco distante da cidade e o Tião tinha pernas boas. Levar recados e buscar a correspondência, comprar alguma coisa, isto era com ele. (Borges, [19-], p. 65)

Figura 1 -

Menino negro acolhido pela família de Domitila Borges.

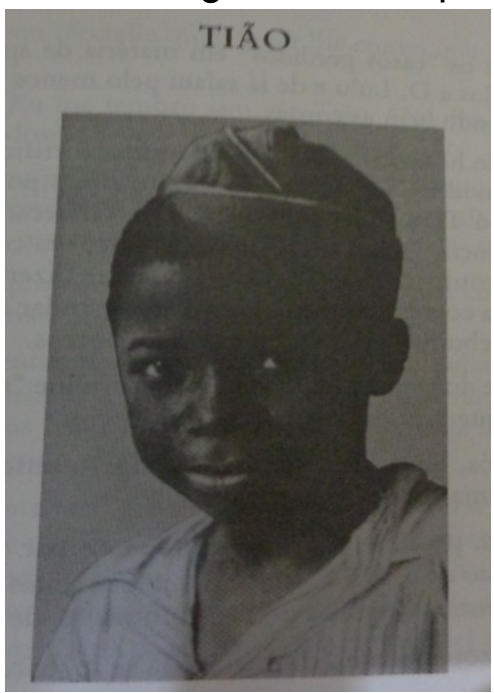

Fonte: Borges, [19-], p. 65. 
Carneiro (2011), ao estudar as práticas familiares no processo de distinção geracional criança/adulto de uma família abastada da cidade de Caetité Bahia (19101930), também constatou a existência da prática de adoção de crianças negras órfãs por integrantes daquela família. Assim como observado por Carneiro (2011, p. 72), por meio do relato acima, percebe-se que as crianças que eram tomadas para a adoção "deveriam "recompensar" de alguma forma, geralmente com trabalhos domésticos, o esforço empreendido em prol de cuidados e gastos dispensados a elas." Tais evidências corroboram a distinção vivenciada na infância por negros e não negros.

Diferentemente do pertencimento étnico-racial, o pertencimento social é melhor perceptível nas fontes estudadas. É possível apreendê-lo nas fotografias incluídas no texto pelos autores e nas descrições feitas sobre a residência, os brinquedos, a escola e demais espaços frequentados na infância.

Observou-se, assim, a dissonância entre padrões de vida experienciados na infância pobre e na infância rica. Na infância daqueles que se declaravam pobres - três dos doze autores analisados - os brinquedos eram, predominantemente, artesanais, muitas vezes construídos pelas próprias crianças, como mostra Diniz (2001, p. 25): "Brinquedo comprado em loja era só mesmo para menino rico. Ter velocípede era sinal de status. Filho de pobre tinha que se virar. Brincava-se, sobretudo, de cavalo de pau."

Já as crianças pertencentes às famílias abastadas podiam usufruir de brinquedos e roupas mais sofisticados, como conta Queiroz (1997, p. 17): "Ganhamos, certa ocasião, lindos vestidinhos confeccionados em seda georgete, [...] ninguém tinha nada igual. [...] ganhamos bonecas grandes e bonitas, como também nenhuma outra menina possuía."

A esse respeito, ao estudarem a infância de mulheres, em sua maioria negras em Minas Gerais no mesmo período, Jinzenji et al (2012) descrevem que a falta desses brinquedos bem como de calçados e roupas foi bastante mencionada por esse segmento da população, o que evidencia o entrecruzamento das variáveis classe social e pertencimento étnico-racial sobre os modos de viver a infância em Minas Gerais na primeira metade do século 20.

Outro ponto de distinção social na infância pode ser percebido por meio da existência da babá nas famílias que detinham maior poder econômico, como é possível verificar nas obras de Beatriz B. Martins, Vanda F. Queiroz, Carlos C. Filho, Pitucha G. Renault e Elzira P. Neves. De acordo com esses autores as babás eram, em sua maioria, mulheres negras: "Quem me servia de babá era a Felícia, afilhada de papai e de Umbelinda e era filha de uma escrava deles. A mãe havia morrido e ela continuou conosco" (Neves, 1984, p. 12). Tais mulheres ou moças, como são chamadas em alguns casos, auxiliavam no banho, na alimentação, na condução até a escola: "Após um dia de ingênuas brincadeiras, Coló nos chamava. Dava-nos banho, na saleta, dentro de uma grande bacia de alumínio. [...] Ela era uma mocinha meio espevitada, mas muito caprichosa. Arrumava a casa e cuidava das crianças" (Queiroz, 1997, p. 11).

Beatriz B. Martins, que passou parte de sua infância na suntuosa casa de seu pai, importante médico de Belo Horizonte, publicou em seu relato a fotografia de uma das três babás de sua infância: 
Figura 2 -

A menina Beatriz B. Martins e sua primeira babá.

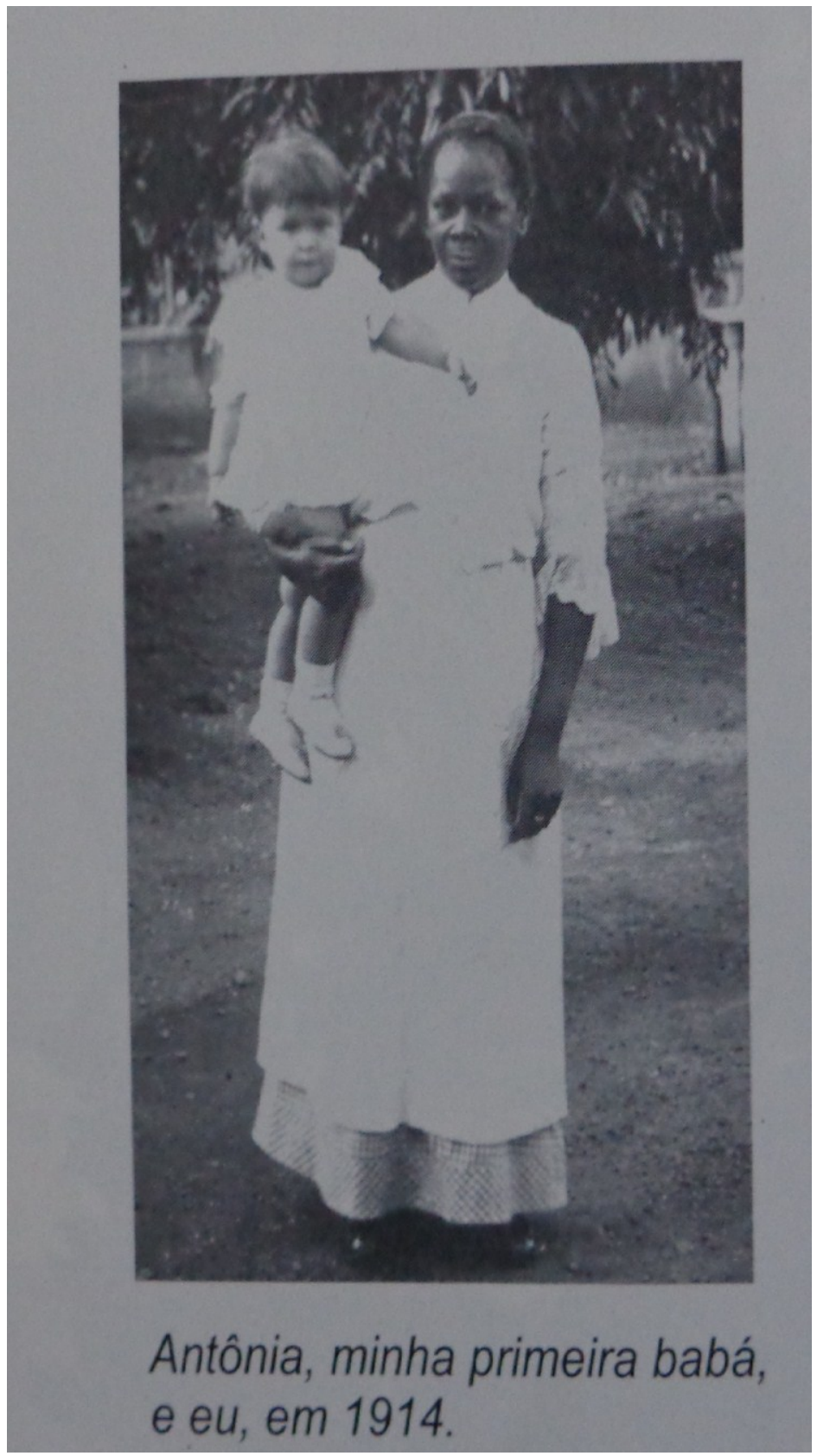

Fonte: Martins, 2000, p. 225.

O mesmo ocorreu com Pitucha G. Renault que, embora seja oriunda de uma família menos abastada de Belo Horizonte, também cita a presença da babá na infância: "Da turma dos meus cinco irmãos mais velhos quem cuidara era a Lalada, e dos cinco menores, de mim para baixo, a Angelina [...] uma preta bonita e viçosa, [...]." (Renault, [19-], p.15).

Carlos C. Filho, diferentemente das autoras supracitadas, menciona outro perfil de babá com o qual teve contato na fazenda dos pais em Campos Gerais:

Fernando era um preto [...] vindo do final da escravidão no Brasil, se bem que não tivesse sido escravo. [...]. Para mim foi mesmo uma verdadeira babá, em certo período de minha infância. Era o meu companheiro 
inseparável para quase tudo: levava-me ao cinema, ao circo de cavalinhos e, finalmente me contava histórias antes de dormir. (Caiafa Filho, 1986, p. 46)

Já a infância daqueles que se declaram pobres apresenta como característica principal a presença do trabalho:

Desde criancinha, já me virava para ganhar um dinheirinho. Ao completar meus oitos anos, empreguei-me numa pequena casa de comércio de secos e molhados [...]. Trabalhava no comércio das onze horas do dia até as nove da noite, visto que das sete as onze era meu horário escolar. (Costa, 1979, p. 21)

No caso de José H. Diniz o trabalho aparece por volta dos 12 anos. Embora fizesse outras atividades antes desse período, como levar almoço para os pais e irmãos mais velhos que trabalhavam na roça e cuidar da horta, é ao terminar o curso primário que se dá sua inserção efetiva no mundo do trabalho:

Trabalhava como candeeiro, guiando a carroça de bois ou o arado. [...] Depois, fui trabalhar no comércio.[...] Foram quase dois anos de trabalho semi-escravo. Não tinha carteira assinada, nem pagamento do salário legal. Chegava ao serviço às sete da manhã, de segunda à segunda. $O$ horário de saída dependia do humor do patrão, geralmente lá pelas sete ou oito horas da noite. (Diniz, 2001, p. 45,46)

Segundo Kassouf (2007) o trabalho infantil fez parte da vida da maior parte das crianças pobres no Brasil. Além de ser visto como um auxílio indispensável no esforço conjunto de sobrevivência familiar, há, de modo geral, uma representação compartilhada entre as classes populares de que exercer atividades ocupacionais é um dos melhores modos de se educar a infância: o trabalho é visto como uma fundamental instância educativa (Brandão, 1999; Galvão, 2013). Nos relatos acima o trabalho é realizado concomitantemente com a convivência familiar, o brincar e o estudar, ou seja, com atividades que, em nossa representação contemporânea - e de sujeitos escolarizados -, seriam específicas da infância. Distanciam-se, nesse sentido, dos relatos sobre trabalhadores infantis das fábricas dos grandes centros urbanos nas primeiras décadas do século 20, como demonstrado por Rizzini (1993), que tinham, no trabalho, sua única ocupação.

\section{Infância rural e infância urbana}

Na primeira metade do século 20, conforme mostram os dados estatísticos do IBGE, a maioria da população de Minas Gerais, $70 \%$, era moradora do espaço rural. O restante, $30 \%$, compunha os quadros urbanos e suburbanos.

Pela análise dos dados coletados foi possível ver divergências e também confluências nas representações construídas sobre a infância com base no espaço vivido. Dos doze autores analisados cinco vivenciaram a infância em fazendas, sete no espaço urbano e três tiveram contato tanto com o rural quanto com o urbano. 
A fazenda aparece como o principal espaço em torno do qual são reconstruídas as lembranças da vida da criança rural. Os autores que narram a infância vivenciada na fazenda tendem a descrevê-la com riqueza de detalhes, aproximando o leitor de um universo que parece perfeito para ter as melhores e mais encantadoras experiências dessa fase da vida. Para isso, destacam os sons, os cheiros, as cores de maneira poética e saudosista, inclusive, contrapondo-a com a infância urbana, como é o caso de Vanda F. Queiroz:

\begin{abstract}
Era assim o nosso Tipis. Pequeno paraíso onde passei o tempo que restava de minha infância, em saudável contato com a natureza e a pitoresca vida na roça. Quem mora sempre na cidade desconhece o infinito universo de experiências bonitas, aos que tem o privilégio de viver na área bucólica do interior. (Queiroz, 1997, p. 34)
\end{abstract}

É nesse tom que Vanda F. Queiroz descreve, detalhadamente, sua infância na fazenda dos Tipis, ao lado da mãe, das três irmãs e dos empregados. Os sabores das comidas, dos doces, as brincadeiras, os cheiros, as cores, os banhos de rio. Enfim, são muitas as lembranças que preenchem as 181 páginas repletas de detalhes de uma saudosa infância saboreada no meio rural.

Lauwe (1991), ao estudar a infância ao longo dos séculos 19 e 20 na França, tendo como principais fontes autobiografias romances e o cinema, constatou que "a infância rural é raramente infeliz. [...] Enquanto tipo de sociedade, a comunidade rural se beneficia de uma intimidade, de uma possibilidade de enraizamento, de tradição e de festas que são também características tidas como favoráveis à criança" (p. 314). Todavia, algumas pesquisas mostram que, mais do que uma realidade vivida pela maioria das crianças, a felicidade, a ingenuidade e a pureza supostamente típicas da infância rural, é uma representação que foi construída ao longo do século 20 por determinados grupos sociais e disseminadas em veículos diversos. Diante da pergunta sobre como havia sido a vida quando eram meninas as mulheres entrevistadas por Jinzenji et al (2012), em sua maioria negras e de origem rural que foram crianças em Minas Gerais em meados do século 20, afirmam que não tiveram infância. Contraditoriamente à ideia de feliz infância supracitada, a intensa rotina de trabalho vivida, na agricultura e nos afazeres domésticos, na própria casa ou na casa de outras famílias, para quem eram doadas para serem criadas, nos possibilita desmistificar o rural como espaço privilegiado para se viver a infância, uma vez que ele não se encontra isento das contradições e desigualdades de classe, de gênero e de raça/etnia, características das sociedades em determinadas épocas.

Se no corpus analisado a fazenda predomina como espaço representativo da infância rural, a infância nas cidades tem como principal lócus o quintal. As cidades referidas pelos autores das memórias e autobiografias na primeira metade do século 20 , conforme evidenciam os dados estatísticos do IBGE, possuíam baixo número de habitantes no espaço da sede, sendo que algumas, inclusive, apresentavam características muito próximas ao que, contemporaneamente, identificamos ao rural. 
O quintal aparece, assim, como espaço mais significativo para a realização das atividades infantis, como aponta Elzira A. P. Neves (1984), que viveu sua infância na cidade de Curvelo3: "Fomos para o quintal brincar de fazer comidinha e de comadre" ( $p$. 12). Helenice V. B. Barracho (2006), por sua vez, na crônica intitulada A magia de um quintal, assim descreve suas experiências nesse espaço, por volta de 1935, em Conselheiro Pena ${ }^{4}$, uma das cidades em que viveu na infância:

O quintal era meu mundo. [...] Um limoeiro com seus enormes galhos arrastando pelo chão, dava-nos uma gostosa sombra e sob ela montávamos nossas casinhas com fogãozinho de lata toda desenhada, panelinhas de barro, talheres de gravetos para fazer nossa comidinha de mentira. (Barracho, 2006, p. 54)

O quintal marca também as infâncias de Pitucha G. Renault e Beatriz B. Martins, ambas de Belo Horizonte. Para Renault ([19-], p.16), o quintal era o local onde "a turma miúda" se reunia depois do "ajantarado" para brincar de teatro, procissão, enterro de gatos, coelhos ou passarinhos. Beatriz B. Martins (2000, p. 23), por sua vez, cita que no quintal de sua casa, repleto de árvores frutíferas, ela subia e se sentava nos galhos da enorme mangueira, sempre com um livro nas mãos.

Vale ressaltar que as autoras acima citadas representam a infância em espaços privilegiados da cidade, mais precisamente na Rua São Paulo e na Rua da Bahia, regiões centrais da cidade. De acordo com os dados do IBGE a capital Belo Horizonte 5 em 1950 possuía cerca de $76 \%$ dos habitantes situados no quadro suburbano da cidade, sobre os quais não temos nenhuma representação da infância no conjunto das fontes analisadas neste estudo.

Percebe-se, ainda, que as fronteiras entre o rural e o urbano eram, em alguns casos, bastante tênues, como no relato de José H. Diniz:

Passei minha infância em Contagem 6 [...] A família trabalhava na roça [...] lá pelas onze, eu já tinha levado o almoço para meu pai e meus irmãos mais velhos e estava pronto para ir à escola. Pouco depois disso, passava a turminha da Rua da Formiga [...] Seguíamos um bando de quatro ou cinco garotos por uma rua de poucas casas que, na época, era simplesmente conhecida por beco. (Diniz, 2001, p.23)

3 Segundo a Enciclopédia dos municípios, o censo de 1950 aponta que o município de Curvelo era composto por 42.825 habitantes dos quais 13.633 ocupavam a sede, onde residia Elzira Augusta Pereira Neves (IBGE, 1957, p. 574).

4 De acordo com a Enciclopédia dos municípios brasileiros (v.2 4, 1957), o recenseamento de 1950 aponta que a população total de Conselheiro Pena era 47.097 habitantes, dos quais $7,84 \%$ residiam na sede, isto é, a população urbana era composta por um número pequeno de habitantes, em torno de 3.694, enquanto o quadro rural era composto por $78,86 \%$ da população (IBGE, 1957, p. 511).

5 Em 1950 o censo do IBGE apontava que a capital mineira tinha um total de 352.724 habitantes, dos quais $70.529(20 \%)$ compunham o quadro urbano. A maioria da população - 270.324 habitantes $(76 \%)$ - residia na área denominada pelo IBGE como suburbana. Os habitantes que constituíam o quadro rural representavam a minoria da população: 11.871 habitantes (IBGE, 1957, p. 165).

6 Conforme a Enciclopédia dos municípios (v. 24, 1957), o censo de 1950 apontava que o município de Contagem era composto por 6.022 habitantes, sendo que desse total a minoria residia no espaço da sede, 33,17\%, isto é 1.998 habitantes (IBGE, 1957, p. 514). 
O relato acima indica que a infância do autor foi vivenciada em constante contato com o rural e o urbano, espaços que pareciam apresentar localização geográfica bastante próximas. Essa proximidade, junto com o olhar adulto sobre a infância vivida em uma Contagem completamente diferente da dos dias atuais, parece influenciar inclusive no modo como o autor caracteriza sua infância descrevendo as atividades exercidas nesse período da vida como típicas da infância rural: "às vezes quedo-me de olhos fechados e fico a me ver de calças curtas, pés descalços, a fazer o trabalho próprio das crianças de meio rural daquela época: descascar e debulhar o milho, cuidar da horta" (Diniz, 2001, p. 53).

Desse modo podemos observar que a tradicional oposição entre campo e cidade presente ao longo da história ocidental deve ser vista de modo mais complexo, na medida em que "a cidade e o campo, mais que espaços físicos, traduzem diferentes ordenações da vida social, engendrando hábitos, valores e atitudes diversas" (Gouvêa, 2004, p. 175).

Além do quintal, percebeu-se a existência de outros espaços urbanos a que tinham acesso algumas crianças nas cidades, como o cinema e os clubes: "O Minas Tênis Clube tinha sido inaugurado havia pouco, e frequenta-lo tornou-se para a meninada um hábito salutar, irresistível" (Renault, [19-], p. 8); assim relata Pitucha G. Renault, oriunda da classe média de Belo Horizonte. O cinema, por sua vez, era um local frequentado nas infâncias de Carlos C. Filho, Helenice V. B. Barracho e Luís G. dos Santos. Diferente foi a experiência de Oswaldo J. da Costa (1979, p. 13) que, tendo vivenciado sua infância em Bocaiúva afirma "não conhecíamos luz elétrica, cinema, rádio ou outro qualquer divertimento que nos prendesse a atenção."

\section{Infância e religiosidade}

Nas fontes utilizadas no estudo que deu origem a este artigo as práticas referentes à religião católica ${ }^{7}$ são citadas por todos os sujeitos. Os autores nos oferecem indícios sobre o pertencimento à religião católica em diferentes momentos da escrita: quando se referem à infância, à idade adulta, à escola, ao casamento.

De acordo com os relatos Domitila Borges ([19-], p. 106), que na vida adulta se tornou freira, percebe-se que as famílias exerciam papel importante na introdução das crianças às práticas da religião católica: "Desde muito criança fui profundamente marcada pela Semana Santa. O silêncio que se guardava em casa, o jejum rigoroso de meus pais, a intensificação das orações, enfim era todo um conjunto de vivência religiosa que se impunha aos olhos de nós os filhos." A devoção aos santos, outra prática da religião católica, é evidenciada por Vanda F. Queiroz: "Guardo até hoje a devoção à Maria, que aprendi em criança com minha mãe" (1997, p. 32) .

Além das práticas do cotidiano familiar haviam as práticas educativas da própria Igreja, como o catecismo: "Aos sete anos já frequentava o catecismo da Irmã Maria no Colégio" (Santos, 1963, p. 19). O catecismo, para os sujeitos analisados, consistia em uma atividade de preparação em que se aprendiam hábitos e valores proclamados pela Igreja Católica necessários para a inserção na vida cristã marcada pelo rito da primeira

7 Em 1940 as pessoas que se declaravam católicas compunham 97,57\% da população de Minas Gerais (IBGE, 1950). 
comunhão. Desse modo, a criança poderia tanto ter contato direto com os impressos produzidos pela igreja Católica destinados a esse fim, como aprender tais preceitos com a figura do catequista que era quem detinha o impresso.

Segundo Orlando (2013) os catecismos católicos eram impressos de destinação pedagógica para a propagação e conservação da fé e da doutrina da lgreja. Nesse sentido, tais impressos tinham por finalidade a instrução, a inculcação de hábitos e valores religiosos e morais, a modelação de comportamentos, a formação do cristão, o que pode ser percebido no relato de Vanda F. Queiroz:

Aprendi na ponta da língua as lições do catecismo. A professora perguntava: "Quem é Deus?"... e patati-patatá... eu respondia de cor e salteado, como um papagaio: "Deus é um espírito perfeitíssimo, eterno criador do céu e da terra". Nem respirava. "Quantos Deuses há?"... eu entendi "quantos deu Zizá". Pensei que uma pessoa chamada Zizá tinha dado alguma coisa, mas não se sabia quantas. Quando vi por escrito no livrinho, compreendi. (1997, p. 97)

Depois de preparadas pelo catecismo as crianças faziam a primeira comunhão, rito considerado como momento marcante da infância para alguns autores, como, por exemplo, para Vitória M. R. Nogueira (2004, p. 28): "Nesse mesmo dia, 8 de dezembro de 1955, dia da Imaculada Conceição, fiz minha primeira comunhão na Matriz de Nossa Senhora da Conceição, pela manhã. [...] Foi um momento lindo e inesquecível!"

As festas religiosas eram outras práticas consideradas importantes na vivência da infância: "No tempo de criança, as festas religiosas marcavam a vida das pessoas, principalmente no interior. E havia aquelas que tinham certo destaque. Além da Semana Santa, destacavam-se a festa do Divino e a festa do padroeiro" (Diniz, 2001, p. 39). A memória escrita por Luís G. dos Santos é exemplar nesse sentido. No capítulo Festas e casos, composto por doze páginas, ele narra todas as festas, sendo a maioria religiosas, da Diamantina de seu tempo de infância, da Festa de reis em janeiro à Missa do galo em dezembro. Além de mencionar as missas, procissões, novenas e terços rezados nessas comemorações religiosas, Luís G. dos Santos (1986, p. 34) também refere, "o cuscuz com café, biscoitos broas" e até mesmo das danças - marujadas, congado - que essas festas propiciavam, numa verdadeira mistura entre o sagrado e o profano.

A predominância de práticas religiosas católicas nas memórias e autobiografias analisadas mostra a força de um catolicismo pouco institucionalizado no contexto e período analisados e sua influência nos hábitos e costumes da população, abrangendo negros, brancos, pobres, ricos, meninos e meninas em diferentes espaços e tempos.

\section{Infância de novos letrados e infância de estabelecidos na cultura escrita}

Segundo Galvão (2010) cultura escrita pode ser definida como o lugar, simbólico e material, que o escrito ocupa para determinado grupo social, comunidade ou sociedade. O termo novo letrado se refere ao conceito, ainda em construção, utilizado pela referida autora e seus colaboradores, para designar os indivíduos que, em uma linhagem familiar, constituem a primeira geração a se aproximar, de modo mais intenso, da cultura escrita. 
Nesse sentido, os principais critérios, na análise das fontes, para denominar um sujeito como novo letrado diz respeito à predominância da oralidade como forma de transmissão e produção de saberes e a quase ausência da leitura e da escrita no cotidiano da família quando era criança e aos baixos graus de escolaridade dos pais e dos demais componentes da família a que pertence. Em contrapartida, o termo estabelecidos na cultura escrita designa os sujeitos que vivenciaram a infância em famílias letradas, ou seja, em famílias cujos pais ou demais componentes possuíam certo grau de escolaridade e de aproximação com as culturas do escrito.

Das doze obras analisadas três foram escritas por novos letrados e seis por sujeitos pertencentes a famílias letradas. Nas três obras restantes não foi possível identificar claramente a relação das famílias dos autores com as culturas do escrito.

Sobre os novos letrados percebe-se, implicitamente, que a escola, embora apareça de modo muito secundário nas narrativas é, para esses sujeitos, a principal instância que permite a aproximação e participação na cultura escrita, o que os difere dos sujeitos cujos pais são letrados. Nesses últimos casos a escola não representa a principal via de acesso ao escrito, pois, em seus relatos, é possível visualizar o papel de outras instâncias na construção de uma relação de intimidade com a leitura e a escrita.

Nesse sentido, a família8 se configura como instância significativa, sobretudo nos relatos Queiroz (1997), Martins (2000), Renault ([19-]) e Caiafa Filho (1986), todos provenientes de famílias letradas e abastadas. Nessas obras nota-se, no interior da família, a circulação de materiais escritos como revistas e livros de leitura.

Beatriz B. Martins (2000) conta que aguardava ansiosa as férias do fim do ano para desfrutar das histórias de Chiquinho e Jagunço e das várias brincadeiras de quebracabeças do Almanaque Tico-Tico. Os contos da Carochinha, Os desastres de Sofia e As meninas exemplares de Mme. De Ségur eram outras de suas leituras de férias. Além da Revista Tico-Tico, Carlos C. Filho (1986, p. 67) conta que lia ainda as revistas O Malho e Careta, coleções de Sherlock Holmes e História da Liga das Nações. Morando em meio rural e sendo filha de professora leiga, Vanda F. Queiroz (1997) menciona que certa vez sua mãe Ihe dera um livro de leitura, o de Felisberto de Carvalho, com textos em tipo manuscrito.

Além dos relatos que mostram a circulação de materiais escritos percebeu-se, também, práticas de incentivo à leitura por parte dos pais. Na família de Helenice V. B. Barracho (2006, p. 16) o pai é lembrando como incentivador da leitura: "Papai era também uma pessoa severa, porém mais dócil, sensível, que gostava de ouvir música, ler poesias. [...] Procurava sempre as poesias de que mais gostava e depois do jantar lia algumas para nós procurando incentivar-nos à leitura". Já a mãe de Pitucha G. Renault presenteava os filhos aniversariantes com livros: "Mamãe sempre comprava um bom livro: Monteiro Lobato, Machado de Assis, Andersen, Júlio Verne, e nos mandava copiar as palavras que não entendíamos para que ela nos explicasse depois o seu sentido, olhando no dicionário" (Renault, [19-], p. 21).

8 Para um estudo sobre o papel da família na formação de um herdeiro ver Melo (2008). Hist. Educ. [Online] 
Nos relatos dos autores provenientes de famílias letradas e abastadas é ainda citada a prática da leitura nas escolas frequentadas como mostra, por exemplo, Vanda $\mathrm{F}$. Queiroz: "No segundo ano, li todos os livros que me foram sendo passados, depois trocava alguns com as colegas. O preferido foi "Coração", de Amicis" (1997, p. 121).

Diferentemente dos autores provenientes de famílias letradas os novos letrados citam a escola muitas vezes de maneira genérica, como no trecho a seguir: "Aos 7 anos meu pai me matriculou na escola de D. Marianinha Mourão [...] aí eu comecei a aprender as primeiras letras sempre com bom procedimento e aplicação." (Santos, 1963, p. 20). Em outros casos os sujeitos dão ênfase às dificuldades enfrentadas, como nos relatos de Vitória M. R. Nogueira e José H. Diniz, respectivamente:

Cedinho, às 5 horas, tínhamos que acordar para nos dirigir ao Grupo Escolar Inconfidência, onde cursávamos o primário, e íamos a pé. (Nogueira, 2004, p. 28)

Como a grande parte dos colegas, meu destino era interromper a vida escolar e ajudar nos trabalhos da roça. Apenas uma minoria tinha condições de prosseguir a vida estudantil. Naquela época, tudo era mais difícil para os deserdados da sorte. (Diniz, 2001, p. 43)

Em síntese, pode-se afirmar que viver a infância e representá-la em memórias e autobiografias apresenta-se de modo distinto entre aqueles cujas famílias já eram estabelecidas há mais de uma geração nas culturas do escrito e aqueles que denominamos novos letrados. Para os sujeitos oriundos de famílias letradas e abastadas o contato com o escrito não ocorria somente na escola, sendo a família uma instância significativa na aproximação do escrito, por meio da oferta de livros e revistas produzidas para crianças naquele período. Os novos letrados, por sua vez, não mencionam a existência de tais práticas em suas famílias, como também não se referem às práticas de leitura e escrita dentro da escola, representando-a em seus aspectos mais gerais, oferecendo-nos indícios de suas dificuldades de inserção nesse espaço. Além disso, os próprios episódios selecionados para construir as memórias, e o modo de narrá-los, parecem guiados pelos lugares que os autores ocupam no presente. Entre os mais escolarizados, no processo de criação da ilusão biográfica (Bourdieu, 2006), parece necessário encontrar, na infância, indícios de que, no futuro, se tornariam profissionais liberais, leitores e autores. São representações construídas socialmente e que não são, necessariamente, partilhadas por aqueles que, mesmo com a publicação de um livro sobre sua vida, não alcançaram, nem simbólica nem materialmente, o lugar de escritores.

\section{Marcos temporais ou simbólicos que delimitam a infância}

De acordo com Oliveira e Teixeira (2009) as etapas do desenvolvimento humano nos têm sido apresentadas como universais e, portanto, associadas a características comuns a todas as pessoas e a todos os grupos humanos. Sob esse ponto de vista a infância se constituiria como o período em que ocorrem as experiências que surtiriam efeito determinante e configurador em todo o desenvolvimento posterior. Entretanto, a maturação biológica, essencial para o processo de desenvolvimento, não representa a totalidade desse processo. As transformações mais relevantes para a constituição do desenvolvimento tipicamente humano não estão na biologia do indivíduo, mas nas circunstâncias histórico-culturais e nas peculiaridades da trajetória e das experiências de cada sujeito, construídas em relação com os outros. 
A análise dos escritos autobiográficos e memorialísticos nos mostra que os diferentes sujeitos, com pertencimentos sociais, étnico-raciais, de gênero e de origem geográfica diversos, demarcam a infância também de modos distintos, destacando aspectos físicos ou simbólicos específicos para distingui-la das demais fases da vida.

Alguns autores, sobretudo aqueles pertencentes a famílias estabelecidas nas culturas do escrito há mais de uma geração, elegem o ingresso na escola como um marco experiencial que delimita infâncias dentro da infância. Para Vanda F. Queiroz (1997) ter de se distanciar da fazenda dos Tipis para frequentar o colégio significou uma nova etapa dessa fase da vida:

Começaram as aulas. [...] Vesti-me de colegial [...] parecia-me grande a roupa nova, talvez enfunada pela emoção que se avolumava para trás, teimando em querer resgatar - e reter, quem sabe - a parte da infância, que lá ficara, entre morros verde-azulados e risadas cor-de-rosa. [...] Era um momento duplo, portanto, um marco decisivo que repartia em duas a linha de minha caminhada. (p.148)

O mesmo acontece com Maria C. M. da Rocha (1992), para quem o ingresso no Grupo Escolar, localizado na cidade de Antônio Dias, também representou um marco divisor de sua vida: "Morávamos na fazenda, distante uma légua "da rua", e era impossível para uma criança como eu frequentar a escola àquela distância. Finalmente, tudo ajeitado, iniciei uma nova fase na minha vida" (p. 14).

Ao demarcar a escola como um ponto viragem do período da infância para o de outra etapa, tais relatos nos permitem entender que "a infância, como representação dos adultos, abrange tanto o sentido de uma infância longa quanto o sentido de uma subdivisão em fases mais especificas" (Kuhlmann Jr.; Fernandes, 2004, p. 28).

Carlos C. Filho (1986, p. 101), por sua vez, elege, além de aspectos físicos para delimitar a mudança da infância para a puberdade: "Em 1926, no internato, começou a pintar um buçosinho muito micho, [...] Eis-me afinal, entrando nos 13 anos. [...] puberdade à vista! Novas tendências, novos rumos", um marco de natureza cultural e simbólica, a ida para o internato:

Chegou o grande dia da partida para o colégio. Simulando grande alegria pelo fato auspicioso, mas fazendo das tripas coração para não explodir num berreiro daqueles antigos, (que diabo, também eu já estava com 13 $1 / 2$ anos quase um homem!), comecei as despedidas. [...] Por uns rápidos instantes repassei toda minha feliz infância, vertiginosamente, relembrando tudo, tudo o que acontecera até aquele momento. Adeus! Adeus, tempinho gostoso! (Caiafa Filho, 1986, p. 125)

Vale ressaltar que o olhar adulto, nesse caso, influenciou na representação dessa mudança. Carlos C. Filho era médico e por isso a clareza ao escrever sobre as modificações ocorridas, utilizando-se inclusive do termo técnico puberdade. Por outro lado, Luís G. dos Santos, carpinteiro, demarca a mudança da infância para a juventude, quando tinha por volta de 12 anos, de uma maneira distinta, elegendo como marco as condições necessárias à sua subsistência e à de sua família: "Nessa época, pouco tempo me restava para brincar, a não ser aos domingos e nos dias de feriados, e aos dias santos. Freqüentava o grupo, trabalhava na oficina e fazia os mandados de meus pais" 
(Santos, 1986, p. 49). Nesse caso o autor, além de, na escrita da sua vida, pular a etapa da adolescência e passar diretamente para a juventude, ainda nos aponta a diminuição do tempo destinado ao brincar como representativo dessa mudança.

Já na representação de Vanda F. Queiroz (1997) o fim da etapa da infância se anuncia quando aqueles à sua volta começam a reconhecer as meninas como mocinhas:

No início do ano de 1950 (fevereiro), Vandira fez dez anos. Vaneide só esperou chegar maio, e atingiu o patamar dos nove. Não demoraria muito tempo não, e logo passaríamos a escutar o pessoal dizer que "estávamos virando moças". Era o tempo passando... ameaçando marcar dentro em breve o indesejado final de minha infância. (p. 180)

O relato acima, como apontam Jinzenji et al (2012), "demonstra não apenas a historicidade dos vocábulos que definem as diversas etapas da vida, mas também os atributos sociais relacionados ao uso e aos significados dessas denominações" (p. 13). Outra demarcação interessante observada nas memórias e autobiografias diz respeito ao próprio marco cronológico estabelecido pelo sujeito para narrar a infância vivida, como é o caso de Vanda F. Queiroz (1997, p. 7): "As situações tornam-se mais nítidas e começam a definir-se melhor a partir do período em que deveria ter perto de 5 anos. É aí, portanto que posso realmente dar início à minha história." Percebe-se, nesse relato, um contraponto entre a infância como etapa biológica e a infância do ponto de vista sóciohistórico. Analisando-se do ponto de vista biológico a infância pode ser considerada como a etapa da vida que vai do nascimento até a adolescência, por volta dos doze anos. Todavia, nas narrativas de vida, os sujeitos estabelecem um marco inicial da infância que delimita, mais que a infância vivida, a infância lembrada.

\section{Conclusão}

A escola e as instituições de assistência à infância têm sido as principais instituições a registrar vestígios das crianças que viveram em outros tempos. Neste trabalho, ao tomar as memórias e autobiografias como fontes, foi possível ampliar o horizonte de percepção acerca do modo como se articula e se reconstrói o ser criança em cidades mineiras na primeira metade do século 20. Além da escola buscamos apreender outros espaços de sociabilidade da criança: a fazenda, o quintal, as festas religiosas e a família.

Nesse sentido, diante da riqueza e dos limites das próprias fontes, pode-se dizer que em cada relato sobre a infância notam-se especificidades nas representações feitas pelos adultos, o que desvela uma multiplicidade de infâncias engendradas sob a influência de diferentes fatores: gênero, classe social, etnia, religião, origem geográfica e participação na cultura escrita. A própria representação sobre o que distinguiria a infância de outras fases da vida é construída pelos autores a partir de aspectos biológicos, histórico-culturais e simbólicos.

Para o campo da Educação esse diálogo propiciado com a imersão nos aspectos históricos da infância, que no caso desta pesquisa extrapolam o espaço escolar, nos permite aguçar nosso olhar sobre as crianças, sujeitos para os quais se voltam grande parte dos discursos pedagógicos. 


\section{Referências}

ARIĖS, Philippe. História social da criança e da família. Rio de Janeiro: Guanabana Koogan, 1981.

BARRACHO, Helenice Vanetti Barbosa. Os passos da zefinha. Belo Horizonte: Mazza, 2006.

BORGES, Irmã Domitila Ribeiro. O que viveu meu coração. Uberaba: Pinti, [19-].

BOURDIEU, Pierre. A ilusão biográfica. In: FERREIRA, Marieta de Moraes e AMADO, Janaína (orgs.). Usos e abusos da história oral. Rio de Janeiro: FGV, 2006, p.183-191.

BRANDÃO, Carlos Rodrigues. O trabalho de saber: cultura camponesa e escola rural. Porto Alegre: Sulina, 1999.

CAIAFA FILHO, Carlos. Vida de menino: histórias de minha infância. Belo Horizonte: Imprensa oficial, [19-]

CARNEIRO, Giane Araújo Pimentel. As práticas educativas familiares no processo de distinção geracional criança/adulto (Caetité-BA, 1910-1930). Belo Horizonte: UFMG, 2011, 146f. Dissertação (mestrado em Educação). Universidade Federal de Minas Gerais, Programa de Pós-Graduação em Educação.

CHARTIER, Roger. A história cultural: entre práticas e representações. Lisboa: Bertrand Brasil/Difel, 1990.

COSTA, Oswaldo José da. História e mistérios de minha vida. Belo Horizonte: Faculdade de Ciências Médicas de Minas Gerais, 1979.

DINIZ, José Henrique. Pelas trilhas da vida. Belo Horizonte: Mazza, 2001.

FRAGO, A. V. Las autobiografias y diários como fuente historico educativa: tipologia y usos. Revista Teias, Rio de Janeiro: Uerj, v.1, n.1, 2000, p. 1-26.

GALVÃO, Ana Maria de Oliveira, LOPES, Eliane Teixeira Lopes. Território plural: a pesquisa em história da educação. São Paulo, Ática, 2010.

GALVÃO, Ana Maria de Oliveira. Autobiografias e novos letrados: um estudo comparado (Illinois, EUA, e Minas Gerais, Brasil, primeira metade do século 20). Relatório final de pesquisa de Estágio Sênior/Capes. Dekalb, IIl: Northern Illinois University, 2013.

GALVÃO, Ana Maria de Oliveira. História das culturas do escrito: tendências metodológicas e possibilidades de pesquisa. In: MARINHO, Marildes; CARVALHO, Gilcinei Teodoro (orgs.). Cultura escrita e letramento. Belo Horizonte: UFMG, 2010, p. 218-248.

GOUVÊA, Maria Cristina Soares de. O mundo da criança: a construção do infantil na literatura brasileira. Bragança Paulista: USF, 2004.

GRAFF, Harvey. A alfabetização na leitura e na vida: um exemplo do início do século 20. In: GRAFF, Harvey. Os labirintos da alfabetização. Porto Alegre: Artes Médicas, 1994, p. 271-293.

GULLESTAD, Marianne. Infâncias imaginadas: construções do eu e da sociedade nas histórias de vida. Revista Educação \& Sociedade, Campinas: Unicamp, v. 26, n. 91, 2005, p. 509-534.

HUMPHRIES, Jane. Childhood and child labour in the British industrial revolution. New York: Cambridge University Press, 2010. 
INSTITUTO BRASILEIRO DE GEOGRAFIA E ESTATÍSTICA (1957). Enciclopédia dos municípios brasileiros (v. XXIV). Rio de Janeiro. Disponível em <http://biblioteca.ibge.gov.br>. Acesso em 15 mar., 2014.

INSTITUTO BRASILEIRO DE GEOGRAFIA E ESTATÍSTICA. Estatísticas do século 20. Disponível em <http://seculo20.ibge.gov.br/populacionais-sociais-politicas-e-culturais/ busca-por-palavra-chave/populacao >. Acesso em 15 mar., 2014.

JINZENJI, Mônica Y; GALVÃO, Ana Maria de Oliveira; SILVA, Simone A. Memórias da infância em meio rural: a escola e outros espaços de sociabilidade (Minas Gerais - Brasil, 1920-1950). Revista Portuguesa de Educação, Braga: Universidade do Minho, v. 25, n. 2, 2012, p. 9-33.

KASSOUF, Ana Lúcia. O que conhecemos sobre o trabalho infantil? Revista Nova Economia, Belo Horizonte: UFMG, v. 17, n. 2. 2007, p. 324-350.

KUHLMANN JR., Moysés. Infância e educação infantil: uma abordagem história. Porto Alegre: Mediação, 2010.

KUHLMANN JR., Moysés; FERNANDES, Rogério. Sobre a história da infância. In: FARIA FILHO, Luciano Mendes (org.). A infância e sua educação: materiais, práticas e representações (Portugal e Brasil). Belo Horizonte: Autêntica, 2004, p. 15-33.

LAUWE, Marie-José Chomboart. Um outro mundo: a infância. São Paulo: Perspectiva, 1991.

MALUF, Marina; MOTT, Maria Lúcia. Recônditos do mundo feminino. In: SAVENKO, Nicolau (org.). História da vida privada no Brasil. São Paulo: Companhia das Letras, 1998, p. 368-421.

MARTINS, Beatriz Borges. A vida é esta. Belo Horizonte: B. B. Martins, 2000.

MELO, Alfredo César. Saudosismo e crítica social em Casa grande e senzala: a articulação de uma política da memória e de uma utopia. Revista Estudos Avançados, São Paulo: USP, v. 23, n. 67, 2009, p. 279-296.

MELO, Juliana Ferreira de. Modos e condições de participação nas culturas do escrito: Pedro Nava e a formação na família (1903-1913). Belo Horizonte: UFMG, 2008. $243 f$. Dissertação (mestrado em Educação). Universidade Federal de Minas Gerais, Programa de Pós-graduação em Educação.

NEVES, Elzira Augusta Pereira. Minhas lembranças, minhas saudades. [S.I]: [s.n], 1984.

NOGUEIRA, Vitória Maria Rezende. Uma vida de vitória. Belo Horizonte: [s.n], 2004.

OLIVEIRA, Marta Kohl de oliveira; TEIXEIRA, Edival. A questão da periodização do desenvolvimento psicológico. In: OLIVEIRA, Marta Kohl de Oliveira. Cultura e psicologia: questões sobre o desenvolvimento do adulto. São Paulo: Hucitec, 2009, p. 331-359.

ORLANDO, Evilyn de Almeida. Os manuais de catecismo nas trilhas da educação: notas de história. Hist. Educ. (Online). Porto Alegre: Asphe, v. 17, n. 41, 2013, p.159-176.

PESAVENTO, Sandra Jatahy. História \& história cultural. Belo Horizonte: Autêntica, 2003.

QUEIROZ, Vanda Fagundes. Uma candeia na janela: memórias de infância. Curitiba: [s.n], 1997.

RENAULT, Pitucha Godoy. Rua São Paulo 2189: cenas da infância. [S.I]: Impressão Gráfica, [19-]. 
RIZZINI, Irma. Assistência à infância no Brasil: século XIX e XX. Rio de Janeiro: Universitária Santa Úrsola, 1993.

ROCHA, Heloísa Helena Pimenta.; GOUVÊA, Maria Cristina Soares de. Infâncias na História. Educação em Revista, Belo Horizonte: UFMG, v. 26, n. 1, 2010, p.187-194.

ROCHA, Maria Cecília Maurício da. A travessia e a margem: memórias de infância. São Paulo: Pancrom, 1992.

SANTOS, Luís Gonzaga dos. Memórias de um carpinteiro. Belo Horizonte: Bernardo Álvares, 1963.

VALENTE, Ana Lúcia Farah. As irmandades de negros: resistência e repressão. Horizonte: Revista de Estudos de Teologia e Ciências da Religião, Belo Horizonte: PUCMG, v. 9, n. 21, 2011, p. 202-218.

VEIGA, Cynthia Greive. Infância e modernidade: ações, saberes e sujeitos. In: FARIA FILHO, Luciano Mendes (org.). A infância e sua educação. Belo Horizonte: Autêntica, 2004, p. 35-82.

VINCENT, David. Bread, knowledge and freedom: a study of nineteenth-century working class autobiography. London: Methuen, 1981.

VINCENT, David. Literacy and popular culture (England, 1750-1914). Cambridge: Cambridge University Press, 1993.

SIMONE APARECIDA NEVES é graduada em Pedagogia pela Universidade Federal de Minas Gerais.

Endereço: Rua Francisco da Veiga, 379/201 - 30720-490 - Belo Horizonte - MG Brasil.

Email: simonnyneves@yahoo.com.br.

ANA MARIA DE OLIVEIRA GALVÃO é professora na Faculdade de Educação da Universidade Federal de Minas Gerais.

Endereço: Av. Antônio Carlos, 6627 - 31270-901 - Belo Horizonte - MG - Brasil.

Email: anamgalvao@uol.com.br.

Recebido em 7 de agosto de 2014.

Aceito em 30 de setembro de 2015. 